\title{
How is the transition away from fossil fuels doing, and how will the low-carbon future unfold?
}

\author{
Ofélia Q. F. Araújo ${ }^{1}$ José Luiz de Medeiros ${ }^{1}$
}

Published online: 4 June 2021

(c) The Author(s), under exclusive licence to Springer-Verlag GmbH Germany, part of Springer Nature 2021

\section{Graphic abstract}

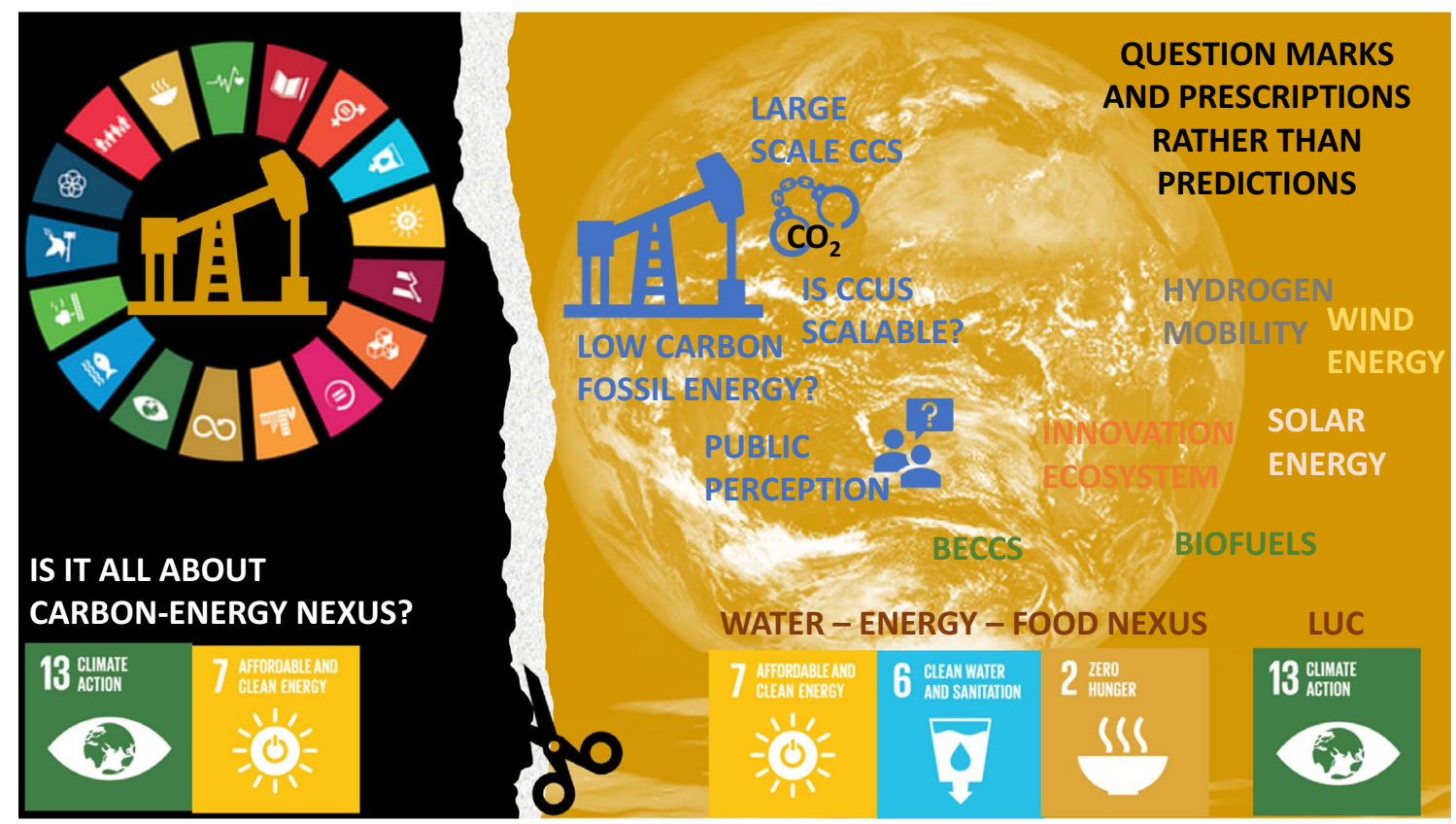

The transition from a fossil-based to a low-carbon economy (based on renewable energies and hydrogen as energy carrier) targets reducing carbon intensity in a short timeframe (one to two decades). The transition driver is limiting global warming caused by greenhouse gases, majorly emitted by fossil fuels and, to a lesser extent, land-use changes. However, the deployment of $\mathrm{CO}_{2}$ management technologies faces the challenge of high investments, the returns on which are in a distant and uncertain future. Uncertainty results from

Ofélia Q. F. Araújo

ofelia@eq.ufrj.br

1 Department of Chemical Engineering, Escola de Química, Federal University of Rio de Janeiro, Av. Athos da Silveira Ramos, 149, Centro de Tecnologia, E, Ilha do Fundão, 21941-972 Rio de Janeiro, RJ, Brazil policy outcomes, technology disruptions, and capital intensity. Additionally, nations hold different social and political perceptions and foresee opportunities to overtake the economic and political scene.

The power generation and industry sectors have two possible ways to abate carbon emissions. One is to retrofit existing plants (e.g., fossil-firing power plants) with CCS (Carbon Capture and Storage) and CCU (Carbon Capture and Utilization). The other is to deploy low-carbon source technologies. However, besides economic penalty on the carbon-emitting process, CCS has main drawbacks that increase uncertainty and retards deployments: (i) geological sites for carbon storage are not evenly spread geographically and most often are distant from the carbon emission sources; (ii) public concerns on carbon leakages and consequential 
effects (e.g., induced seismicity); and (iii) lack of a regulatory framework for post-injection liability. Nevertheless, although the probabilities of leakage are remote, the stored volume of $\mathrm{CO}_{2}$ projected to mitigate global warming is much higher than the volume injected to date. ${ }^{1}$

On the other hands, $\mathrm{CCU}$ aims at monetizing $\mathrm{CO}_{2}$ to reduce the net abatement cost or even result in negative costs (profits). For example, enhanced-oil-recovery (EOR) is a $\mathrm{CCU}$ technology that monetizes $\mathrm{CO}_{2}$ by enhancing the amount of oil produced. Although the oil price is not at its best moment and perspectives are not very optimistic for the future, $\mathrm{CO}_{2}$-EOR is a large-scale technology recognized to meet the scale of emissions abatement needed. CCU alternatives that convert $\mathrm{CO}_{2}$ to value-added products shall grow in the long term but are at earlier process-systems development, small-scaled, and with market size limitations on targeted products. ${ }^{2}$ Furthermore, $\mathrm{CO}_{2}$ conversion finds its main bottleneck in thermodynamics: $\mathrm{CO}_{2}$ requires severe reaction conditions (high temperature and high pressure), despite advancements in catalysts to reduce activation energy. The partial conversion of $\mathrm{CO}_{2}$ achievable adds energy demand for product separation and $\mathrm{CO}_{2}$ recompression for recycling to the reactor. The additional energy demand, if supplied by fossil fuels, reduces the net avoided carbon emission. Also, relevant is the "scale mismatch" between the market demand for the produced chemical and the $\mathrm{CO}_{2}$ "supplied" by the emitting source.

Adopting a carbon pricing policy might accelerate the transition because it gives momentum to CCS and CCUS technologies speeding up the end of the fossil-carbon era. Among ways to accelerate CCS deployment is to invest in the $\mathrm{CO}_{2}$ transportation infrastructure, focusing on national and global carbon hubs. Moreover, the available massive fossil-fuel infrastructure holds back the transition from fossil sources allied to their reliability and affordability in energy supply. The long-living energy infrastructure creates technology lock-in, and much has been invested recently in oil and gas E\&P (Exploration \& Production) despite the carbon awareness. The built infrastructure is the technology ecosystem that holds the carbon-based economy.

However, drivers of the transition exist and are of technological, social, and political nature. As wind and solar technology evolve, so do their economic performances. They progress in their learning curves, and new materials and disruptive technologies are likely to appear, rendering renewables competitive to fossils. In other sectors than energy, reducing carbon emissions faces more technological

\footnotetext{
${ }^{1}$ Natural Resources Research, 2017, 26(1), 89-112.

2 "Carbon Management in the CO2-Rich Natural Gas to Energy Supply-Chain”. Chapter 14 in Carbon Management Technologies, Volume 1, Carbon Removal, Renewable and Nuclear Energy. Editors Subhas K Sikdar and Frank Princiotta. CRC Press, 2020.
}

barriers. Specifically, steel, cement, and chemical industries demand high-temperature thermal energy that can presently be supplied exclusively by fossil-firing processes, with $\mathrm{CO}_{2}$ emissions.

Although CCUS (CCS + CCU) is a crucial carbon management technology class to limit global warming, few large-scale plants exist worldwide due to technical, economic, and commercial issues. ${ }^{3}$ On the other sides, energy security is pushing the transition to low-carbon. Since fossilcarbon sources distribution among nations is uneven, the movement is more substantial in fossil energy-poor countries, whose alternative non-carbon sources are a must-have. Besides being clean, solar photovoltaic and wind, the most prominent alternatives, are proven technologies. They supply the required energy, create jobs-more job-intensive than the O\&G (oil \& gas) industry-and drive economic growth. However, they are at their early development stage. The technology death valley must be crossed with government incentives until they become cost-competitive, fighting against abundant $O \& G$ reserves and installed infrastructure, which turn competition tough for emerging renewable alternatives.

The need to decarbonize is here to stay, and technologies must be of fast deployment (within one to two decades) and large scale. Among CCS technologies, post-combustion is the most mature alternative to capture $\mathrm{CO}_{2}$ and finds use to retrofit existing carbon emissions. CCS heat-integrated to power plants is an important option to mitigate carbon emissions and postpone replacing fossil-carbon-fired power plants. However, the high cost of retrofitting may create a technology lock-in. Therefore, the original power-producing with CCS technologies may remain in use even though new technologies with lower carbon-capture costs are becoming available. ${ }^{4}$

IEA pledges that CCUS is a carbon management class of technologies that reduces emissions in key sectors and removes $\mathrm{CO}_{2}$ to balance unavoidable emissions. Also, IEA foresees a sevenfold increase in hydrogen demand by 2070, requiring complementing green hydrogen (from electrolysis, using renewable electric energy) with blue hydrogen (from gas reforming with CCS) for facing the increasing demand of this energy carrier, feedstock, and fuel. ${ }^{5}$ Hydrogen production from natural gas reforming with CCS reduces grey hydrogen carbon emissions, pairing performance with blue hydrogen. Biomass (gasification) or biomethane reforming produces bio-hydrogen. When coupled to CCS,

\footnotetext{
${ }_{3}$ Energy Environ. Sci., 2018, 11, 1062.

${ }^{4}$ Applied Energy, 2018, 229, 326-334.

5 https://iea.blob.core.windows.net/assets/181b48b4-323f-454d-96fbObb1889d96a9/CCUS_in_clean_energy_transitions.pdf
} 
bio-hydrogen production may result in net-negative carbon emissions. ${ }^{6}$ Similarly, biomass combustion for combined heat and power production is a carbon sink when combined with CCS. ${ }^{7}$ The more stringent the climate targets become, the more urgent the need for near zero-carbon or negative emissions technologies (NET), a niche that fosters bioenergy with CCS (BECCS).

The transition to a low-carbon energy supply causes the increase in renewables in the energy share. However, the vulnerability of renewable energy to climate changes results in fluctuations and intermittencies in energy supply, which impact the reliability of power systems. Compensation for the variability from the supply side is possible with fastreacting gas-fired power plants, with rapid start-up and shutdown operations, or running at partial load capacity. Natural gas is a cleaner fossil energy source in this application, but increasing its use demands rapidly expanding gas infrastructure. The problem approach is of adopting distributed energy grids and managing the demand profile. ${ }^{8}$ Also, transmission systems must expand to interconnect intermittent production plants with fossil-carbon-fired backup plants adequately.

The pathways for reducing carbon intensity in the transport industry comprise electricity, hydrogen, and biofuel-driven vehicles. The current share of electric vehicles, although presently insignificant, is expected to grow as nations worldwide enforce goals to phase out internal combustion engines (ICE). Nevertheless, banning ICE has fleet inertia, which delays the reduction of carbon footprint. Hydrogen mobility through hydrogen fuel cell has a technology readiness level (TRL) relatively high (7 to 8) for passenger cars and light buses but has a prohibitively high cost. Meanwhile, transitioning to low-carbon transportation for passenger vehicles is a technology niche occupied by biofuels, bioethanol, biodiesel in blends (or not) with gasoline and fossil diesel. ${ }^{9}$ It is worth noting that first-generation biofuels are not a preferred long-term alternative due to competition with food destination use of biomass. The second-generation (from residual biomass) biofuel is a promising alternative, but it has yet to overcome the cost barrier. For aviation fuels, synthetic kerosene-chemically and physically similar to fossil aviation kerosene-is technically feasible, but its high cost is a significant obstacle to surpass. Its use would only be possible if enforced by regulations or subsidized by the governments.

Life-cycle GHG emissions assessment is used in California (LCFS, Low-Carbon Fuel Standard) and recently in Brazil (RenovaBio) to award producers and importers with

\footnotetext{
${ }^{6}$ Sustainable Energy Fuels, 2020, 4, 2967-2986.

${ }^{7}$ Renewable and Sustainable Energy Reviews, 2019, 113, 109,251.

${ }^{8}$ Renewable and Sustainable Energy Reviews, 2020, 130, 109,985.

9 Energy Fuels 2021, 35, 7364-7386.
}

tradable decarbonization credits. The amount of CBIOs derives from a calculation with a proprietary GHG model, RenovaCalc, developed by EMBRAPA, the Brazilian Agricultural Research Corporation. The calculation considers the carbon intensity of the biofuel compared to its fossil fuel equivalent (gasoline in the case of bio-ethanol). The amount of $\mathrm{CO}_{2}$ emissions avoided (difference in carbon intensity) provides the environmental efficiency score of the biofuel. CBIOS can be traded and represent additional revenue to the biofuel producer. Thus, it is not a subsidy but a carbon trading mechanism, a voluntary program equivalent to carbon credits. CBIO, unlike the U.S. LCFS program, is considered a co-product and is negotiated separately from the renewable fuel. In Brazil, 221 ethanol plants were certified under RenovaBio by February $2021 .{ }^{10}$ It is worth noting that a Brazilian producer of bio-ethanol exporting to California is eligible to receive credits from both emissions avoidance award mechanisms.

As expected, the decarbonized future does not unfold to a single technology. Instead, there is an ensemble of sitedependent solutions influenced by socio-technical aspects, cost, and geographic niches. The energy transition uses many alternatives, which gradually evolve with time, as no silver bullet exists to replace fossil fuels immediately. For example, limiting temperature rise to $1.5^{\circ} \mathrm{C}$ speeds up transition and intensifies side effects. EIA estimates that moving the netzero goal from 2070 to 2050 would require $50 \%$ more CCUS deployment ${ }^{5}$. Solar, wind, and biomass significantly reduce the carbon footprint but inexorably affect water footprint and impose land-use changes. A decrease in fossil fuel use implies stranding fossil reserves, forcing losses to $O \& G$ producing nations, and decreasing jobs in the fossil-fuel industry. Solar and wind-based energy, among other substitutes, creates job openings but not in the exact locations and with skills specificities that might demand retraining the working force. ${ }^{11}$ The unfolding future is particularly uncertain for the BRICS economies, which, by the year 2030, might respond for $37.7 \%$ of the global gross national product, besides representing more than $50 \%$ of the actual global economic growth and $40 \%$ of the global population. ${ }^{12}$ The impact of innovation, renewable energy consumption and supply, and income on the carbon intensity of such rapid economic development nations are uncertain.

Although foresight is a procedure to prepare wisely for the future, the future has no pact with predictions, mainly derived from unanimous opinions. Therefore, it is undoubtedly challenging to anticipate outcomes. However,

\footnotetext{
10 https://papers.ssrn.com/sol3/papers.cfm?abstract_id=3811678

11 Renewable and Sustainable Energy Transition, 2021, 1, 100,001.

12 Environmental Science and Pollution Research, 2020, 27, 13,86613,881 .
} 
consensual opinions are easier on mature technologies than on those at the early stages of development. Hence, using future scenarios to shape transition paths does not go without criticism, especially regarding roadmaps that support a global policy. Moreover, it is relevant to the analysis of how the future unfolds that technological expectations have causal effects on the way technologies evolve. ${ }^{13}$ Therefore, technology roadmaps as governmental tools to meet social goals (e.g., low-carbon) may define consensus, exclude discordant voices, and "engineer expectations" to influence the direction of socio-technical development ${ }^{13}$.
Finally, the eventuality of the COVID-19 pandemic has slowed down the fossil-renewable energy transition as many national budgets have been tightened, deferring governmental support to renewable energy projects. In addition, supply chains disruptions might also affect ongoing projects, especially solar power plants whose components are from China and East Asia. ${ }^{14}$

Publisher's Note Springer Nature remains neutral with regard to jurisdictional claims in published maps and institutional affiliations.

13 Technological Forecasting \& Social Change, 2012, 79, 530-542.

$\overline{14}$ Energy Research \& Social Science, 2020, 68, 101,633. 